\title{
Effect of breed of cow and calf on recorded milk yield in a dairy ranching herd in Costa Rica
}

\author{
W. KROPF *, A. ARAGON *, N. KÜNZI and W. HAGNAUER ** \\ * Institute of Animal Production, ETH Zurich, Switzerland \\ ** Hda. La Pacifica, Canas, Gte. Costa-Rica
}

In a dairy ranching herd Brahman (BR) cows and their crosses with Simmental (SI) and Brown Swiss (BS) are mated with SI, BS, BR, SI $\times$ BR and Holstein sires. The salable milk production (SMP) of dam is affected by breeding group of cow and breeding group of mated sire. Cows mated with SI, BS and HO have a higher SMP than those mated with BR (higher suckling ability of BR calves). Preweaning weight gain (PWG) of calves are affected by breeding group of dam (BR wean heavier calves because of better mothering ability).

\section{Introduction of European breeds in developing countries by non-surgical embryo transfer}

\author{
W.W. LAMPETER et al. \\ D- 8000 München 22, Veterinärstraße 13
}

Institut für Tierzucht und Tierhygiene der Ludwig-Maximilians-Universität München

Forty two embryos rated good and very good before freezing were imported into Marocco. 30 embryos out of the 42 were judged good and very good after thawing. 28 embryos were transferred non-surgically with a special catheter technique. 12 pregnancies could be manifested by progesterone tests 14 days after transfer and rectal palpations 8 and 12 weeks after transfer. The 42 p. 100 pregnancy rate achieved was satisfying under the circumstances. Further investigations have to be made when the animals out of this experiment have been born to draw conclusions on risks and advantages of the described method.

\section{Dairy performance of crossbreds between Egyptian Baladis and European cattle}

\author{
A. MOSTAGEER * and F. PIRCHNER ** \\ * Animal Breeding Department, Faculty of Agriculture, Cairo University \\ Dokki, Giza, Agypten \\ ** Lehrstuhl für Tierzucht der Technischen Universität München \\ 8050 Freising-Weihenstephan
}

First lactation yield, lactation length and weight at first calving of 5 types of crossbreds were compared with the performance of Baladis, Egyptian Friesians and buffaloes. The crossbreds performance for excelled the pure Baladis and fell into the same range with Friesians and buffaloes. Baladis were conspicuous for very short lactations, but individual crossbreds animals also. 